\title{
Ação do óleo essencial de alecrim (Lippia gracillis Shauer) sobre a microbiota intestinal e o desempenho das aves
}

\author{
[Action of alecrim essential oil (Lippia gracillis Shauer) on intestinal microbiota \\ and bird performance]
}

\section{"Revisão/Review"}

\author{
Grazielle Ferreira Rocha ${ }^{1 *}$, Alan Silva Cerqueira ${ }^{1}$, Arlene Santos Lima $^{1}$, \\ Gregório Murilo Oliveira Júnior ${ }^{2}$
}

\author{
${ }^{1}$ Programa de Pós-Graduação em Zootecnia, Universidade Federal de Sergipe (UFS), São Cristovão-SE, Brasil. \\ ${ }^{2}$ Departamento de Zootecnia, Universidade Federal de Sergipe (UFS), São Cristovão-SE, Brasil. \\ *Autor para correspondência/Corresponding author: E-mail: grazitanna@ hotmail.com
}

\begin{abstract}
Resumo
A presença de uma microbiota benéfica no trato gastrointestinal é um fator importante na otimização da digestão e absorção dos nutrientes indispensável para se obter boa produtividade. Neste sentido, a utilização de antimicrobianos promotores de crescimento na ração dos animais de produção tem como objetivo promover a redução e/ou a morte dos micro-organismos indesejáveis. No entanto, devido à possibilidade de resistência cruzada novas alternativas vêm sendo pesquisadas em substituição a esses antimicrobianos, tais como os óleos essenciais aromáticos. Estes apresentam poucos riscos de acúmulos nos tecidos devido à rápida metabolização e curta meiavida dos seus compostos ativos, sendo que podem atuar diretamente sobre micro-organismos patogênicos. Assim, podem atuar como promotores de crescimento e possivelmente substituir os antibióticos e promotores de crescimento comumente utilizados na dieta dos animais. Os compostos fenólicos, carvacrol e timol, componentes majoritários do óleo essencial de Lippia gracillis Shauer, são os principais responsáveis pela ação antimicrobiana e antioxidante do óleo. No entanto, há poucas pesquisas para avaliar o efeito deste aditivo como promotor de crescimento. Deste modo, devido à potencialidade que estes compostos ativos apresentam diante de bactérias patogênicas e fungos, sua atividade antioxidante, assim como seu potencial como melhoradores de desempenho, o óleo essencial do alecrim torna-se um potencial aditivo para ser adicionado às dietas de aves. Objetivou-se com esse artigo de revisão elucidar o modo de ação do óleo essencial de alecrim (Lippia gracillis Shauer) sobre a microbiota intestinal das aves como antimicrobianos melhoradores de desempenho.
\end{abstract}

Palavras-chave: ação antimicrobiana; carvacrol; desempenho; micro-organismos; timol.

\begin{abstract}
The presence of a beneficial microbiota in the gastrointestinal tract is an important factor in the optimization of nutrient digestion and absorption, which are indispensable for good productivity. The use of antimicrobial growth promoters in animal production is aimed at reducing and/or killing undesirable microorganisms. However, due to the possibility of cross-resistance, new alternatives have been researched to replace these antimicrobials, as is the case of aromatic essential oils. In addition to posing little risk of accumulation in the tissues due to the rapid metabolization and short half-life of their active compounds, these oils act directly on pathogenic microorganisms. As such, they can act as growth promoters and possibly replace the antibiotics and growth promoters commonly used in animal diets. The phenolic compounds carvacrol and thymol, major components of Lippia gracilis Schauer essential oil, are the main compounds responsible for its antimicrobial and antioxidant action. Nonetheless, there is little research investigating the effect of this additive as a growth promoter. Therefore, considering the effect of these active compounds against pathogenic bacteria and fungi, antioxidant activity, as well as potential as performance enhancers, Lippia gracilis Schauer essential oil appears to be a possible additive to be used in poultry diets. This review article proposes to elucidate the mode of action of Lippia gracilis Schauer essential oil on the intestinal microbiota of poultry as an antimicrobial performance enhancer.
\end{abstract}

Keywords: antimicrobial action; carvacrol; microorganisms; performance; thymol. 


\section{Introdução}

Os sistemas de criação atuais de aves, principalmente as criações intensivas, podem proporcionar maior desafio sanitário devido à maior densidade, fato que pode ocasionar maior susceptibilidade aos patógenos e vetores. Desta maneira, vêm sendo comumente utilizados promotores de crescimento a fim de manter a produtividade e qualidade na produção.

$\mathrm{O}$ uso de antimicrobianos tem sido cada vez mais avaliado e, em muitas vezes restringido, devido à possibilidade de resistência bacteriana e à transmissão cruzada por bactérias patogênicas em humanos; fato este utilizado como ponto de estrangulamento na comercialização do produto. Assim, torna-se necessário buscar alternativas naturais que visam substituir o uso de antimicrobianos como promotores de crescimento com o intuito de atender às exigências de mercado, obter produtos sustentáveis e manter ou melhorar o desempenho das aves.

Dentro deste conceito, os óleos essenciais têm se mostrado uma alternativa viável por apresentarem efeito antimicrobiano significativo (Jang et al., 2007; Santurio et al., 2007), apresentarem outras propriedades, tais como estímulo das enzimas digestivas e pancreáticas (Jang et al., 2007; Basmacioğlu Malayoğlu et al., 2010) e efeito antioxidante (Racanicci et al., 2004; 2008; Traesel et al., 2011).

O alecrim, Lippia gracillis Shauer, é uma planta pertencente à família Verbenaceae, originária da região Nordeste do Brasil. Possui aproximadamente $2,5 \mathrm{~m}$ de altura, folhas pequenas, flores brancas e são capazes de produzir óleos essenciais, os quais apresentam em sua composição p-cimeno, $\alpha$-pineno, $\beta$-cariofileno, 4-terpineol, $\gamma$ terpineno (Bitu et al., 2012), sendo o timol e o carvacrol, os princípios ativos em maior concentração (Albuquerque et al., 2006; Bitu et al., 2012).

Visto que há um crescente interesse no uso de aditivos fitogênicos na alimentação de aves, e que há poucas pesquisas relacionadas ao uso de óleos essenciais e seus benefícios na produção de aves, em especial com óleo de alecrim, objetivouse com esse artigo de revisão elucidar o modo de ação do óleo essencial de alecrim (Lippia gracillis Shauer) sobre a microbiota intestinal das aves como antimicrobianos melhoradores de desempenho.

\section{Microbiota intestinal das aves e sua relação com o desempenho}

A vida do homem e dos animais tem importante relação com os micro-organismos presentes no corpo. A microbiota intestinal exerce papel fundamental na saúde, bem-estar, e na produtividade dos animais (Callaway et al., 2008). Contudo, a população microbiana no organismo é dependente do tipo de dieta que o animal consome, ambiente e seu estado imunológico.

Dentro deste conceito, a alteração de $\mathrm{pH}$, a produção de secreção enzimática no organismo, a velocidade de passagem do bolo alimentar e até mesmo a concentração de ácidos graxos voláteis interferem na população da microbiota encontrada ao longo do trato gastrointestinal (Lu et al., 2003) e, por consequência, irá interferir no desempenho das aves.

Cerca de $90 \%$ da microbiota intestinal das aves é composta por bactérias do gênero Lactobacillus, Bifidobacterium, Bacteroides, Fusobacterium e Eubacterium, sendo os 10\% restantes composta por Escherichia coli, Clostridium spp. e Salmonella spp., bactérias consideradas patogênicas (Névoa et al., 2013).

Lactobacillus, que fazem parte da microbiota natural, estimulam a secreção de imunoglobulina IgA intestinal, que auxilia na imunidade e, atuam contra o crescimento de bactérias indesejáveis (Andreatti-Filho, 2007). Além disso, pelo fato de produzirem ácido lático e acético, reduzem o $\mathrm{pH}$, consequentemente dificultam o crescimento de bactérias patogênicas (Névoa et al., 2013).

Outro grupo benéfico que também faz parte da microbiota intestinal é o gênero Bifidobacterium. As bactérias pertencentes a esse grupo são capazes de produzir lactato e acetato, desempenham ações tais como redução do $\mathrm{pH}$ do meio, efeito antibacteriano, favorecem a produção de vitaminas do grupo $\mathrm{B}$ e bacteriocinas, intensificam o sistema imune mediante ativação de macrófagos contra células malignas, auxílio na digestão e absorção de nutrientes pelo seu envolvimento na bioquímica intestinal, especialmente em relação à ação sobre os sais biliares (Leahy et al., 2005; Andreatti-Filho, 2007; Figueira et al., 2014).

As bactérias comensais proporcionam maior atividade de enzimas digestivas, permitem maior disponibilidade de nutrientes, tais como ácidos graxos de cadeia curta, aminoácidos e vitaminas, e 
redução da colonização de bactérias indesejáveis comparados aos patógenos específicos livres (Willing e Van Kessel, 2009). A população da microbiota também pode afetar a morfometria da parede intestinal e induzir as reações imunes adaptativa e inata, que podem interferir no gasto energético do animal (Humphrey e Klasing, 2004; Teirlynck et al., 2009).

A presença de uma microbiota benéfica no trato gastrointestinal é um fator importante na otimização da digestão e absorção dos nutrientes indispensável para se obter boa produtividade, visto que a colonização de micro-organismos benéficos pode provocar um equilíbrio através da competição por nutrientes e sítios de ligação na mucosa, e pela liberação de bacteriocinas (Lan et al., 2005; Figueira et al., 2014). Entretanto, algumas bactérias que compõe a microbiota normal de aves, em especial as patogênicas, produzem enzimas que afetam a integridade da mucosa intestinal e competem por nutrientes com o hospedeiro, o que pode exercer efeitos deletérios no desempenho dos animais (Oviedo-Rondón, 2009).

O desequilíbrio da microbiota pode ser provocado por fatores tanto endógenos quanto exógenos, tais como, más condições higiênicas e sanitárias da criação, estresse, alimentação inadequada, intoxicação e enfermidade, que levam ao aumento da população bacteriana patogênica (Figueira et al., 2014). Estes micro-organismos são responsáveis por provocar déficits nutricionais, devido à competição por nutrientes com 0 hospedeiro, diminuem a absorção de nutrientes, aumentam a espessura da mucosa e a velocidade de passagem da digesta no trato gastrointestinal, o que resultará na maior excreção de metabólitos e toxinas que desencadeiam desordens gastrointestinais (Flemming e Freitas, 2005; Figueira et al., 2014), ocasionando declínio na produção destes animais.

A utilização de antimicrobianos promotores de crescimento na ração dos animais de produção, tem como objetivo promover a redução e/ou a morte dos micro-organismos indesejáveis, assim como também, pode interromper no seu crescimento e na sua reprodução (Costa et al., 2007), por agirem sobre a estrutura do microorganismo, penetrando a célula e, provocando a inibição do processo metabólico essencial à vida ou interferindo no desenvolvimento desses organismos (Santos et al., 2008).

\section{Óleos essenciais}

$\mathrm{Na}$ produção animal, a busca por aditivos que venham a substituir os antibióticos como promotores de crescimento e beneficiar a microbiota intestinal tem-se destacado. Com isso, as plantas aromáticas e seus óleos essenciais têm despertado interesse da comunidade cientifica como uma alternativa aos antimicrobianos químicos utilizados como promotores de crescimento em animais de interesse zootécnico (Valero et al., 2014). Esses produtos possuem vantagens sobre antibióticos comerciais frequentemente utilizados, pois possuem pequena capacidade de deixar resíduos, na maioria das vezes são reconhecidos pelos consumidores como seguros e bastante usados na indústria de alimentos (Brenes e Roura, 2010).

Os óleos essenciais são constituídos por complexas misturas de substâncias voláteis, geralmente lipofílicas (Teixeira et al., 2013), incluindo uma série de hidrocarbonetos terpênicos, ésteres, ácidos orgânicos, aldeídos, cetonas, fenóis, entre outros, os quais se apresentam em diferentes concentrações na planta (Bona et al., 2012). As técnicas utilizadas para obtenção dos óleos essenciais podem ser a destilação a vapor d'água ou a atividade enzimática seguida de destilação a vapor d'água (Toledo et al., 2007).

Fatores - biológicos tais como a espécie de planta, local de plantio e condições de colheita; de produção, como o tipo de extração, destilação e estabilidade; e condições de armazenamento como a intensidade da luz, temperatura e tempo de estocagem - podem influenciar na composição dos óleos essenciais (Huyghebaert et al., 2011), em especial dos princípios ativos. A existência desses fatores pode alterar a qualidade dos óleos essenciais e influenciar a resposta sobre o desempenho dos animais.

Os princípios ativos são substâncias provenientes do metabolismo secundário das plantas e são responsáveis pelos efeitos terapêuticos das mesmas (Fernandes et al., 2015). Em uma mesma planta pode existir mais de um princípio ativo em diferentes concentrações e diversas plantas pode conter o mesmo princípio ativo. Ainda pode ocorrer sinergismo entre óleos essenciais e/ou seus princípios ativos tornando-os mais eficazes (Zhang et al., 2005).

Os princípios ativos dos extratos vegetais são absorvidos no intestino pelos enterócitos e metabolizados rapidamente no organismo dos animais, sendo esses eliminados pela urina, através 
da formação de compostos polares, ou pela respiração como $\mathrm{CO}_{2}$, em que a rápida metabolização e curta meia-vida dos compostos ativos não permite o seu acúmulo nos tecidos, por isto, poucos são os riscos existentes (Kohlert et al., 2000).

Diferentes estudos comprovaram que os aditivos fitogênicos possuem efeito antioxidante (Racanicci et al., 2004; 2008; Traesel et al., 2011), atuam sobre micro-organismos patogênicos encontrados no intestino das aves (Oviedo-Rondón et al., 2006; Jang et al., 2007; Santurio et al., 2007; Silva et al., 2009; Bona et al., 2012) e melhoram o desempenho de frangos de corte (Agostini et al., 2012; Cardoso et al., 2012; Hong et al., 2012; Koiyama et al., 2014).

O aumento da palatabilidade, consequentemente o aumento do consumo de ração, estímulo à secreção de enzimas digestivas, endócrina e da resposta imune, aumento da motilidade gástrica e intestinal, atividade antibacteriana, antiviral, anti-helmíntica, coccidiostática, anti-inflamatória e antioxidante, e ação pigmentante são algumas das ações provocadas pela utilização de óleos essenciais (Basmacioğlu Malayoğlu et al., 2010), o que podem torná-los potenciais substitutos dos antibióticos melhoradores do desempenho.

A adição de óleos essenciais na alimentação de aves, em substituição aos promotores de crescimento, evita que bactérias patogênicas se alojem na mucosa intestinal, proporcionando melhorias na flora intestinal e, consequentemente, no desempenho produtivo (Fernandez et al., 2015). A atividade antimicrobiana dos óleos essenciais provoca benefícios para os animais de produção, no entanto, não há total esclarecimento quanto ao método de ação antimicrobiano (Leite et al., 2012).

Segundo Bona et al. (2012), a maioria dos óleos essenciais desempenha seu efeito antimicrobiano através de sua ação na estrutura da parede celular bacteriana, desnaturando e coagulando as proteínas. A alteração da permeabilidade da membrana das paredes celulares das bactérias ocorre devido ao caráter lipofílico dos óleos essenciais que se acumulam nas membranas, de forma que alteram a permeabilidade da membrana citoplasmática por íons de hidrogênio $(\mathrm{H}+)$ e potássio $(\mathrm{K}+)$ (Dorman e Deans, 2000; Bona et al., 2012).

A alteração dos gradientes por meio de íons prejudica os processos essenciais da célula como transporte de elétrons, translocação de proteínas, fases da fosforilação e também outras reações dependentes de enzimas, causando perda do controle quimiosmótico da célula afetada e, por conseguinte, morte bacteriana (Dorman e Deans, 2000).

Entretanto, apesar dos óleos essenciais e seus componentes serem conhecidos por serem efetivos contra uma série de micro-organismos (Ferro et al., 2016), autores demonstram que bactérias Gram-positivas são mais sensíveis quando comparadas às bactérias Gram-negativas (Hentz e Santim, 2007; Soares et al., 2013; Nascimento et al., 2014).

Todas as bactérias Gram-negativas possuem uma membrana externa composta por moléculas de lipopolissacarídeos que lhes conferem uma superfície hidrofílica, que dificulta a permeabilidade das substâncias hidrofóbicas, tais como os óleos essenciais, o que aumenta a resistência destas bactérias Gram-negativas a esses aditivos (Dorman e Deans, 2000).

O lipopolissacarídeo que compõe a membrana externa das bactérias Gram-negativas é composto por três unidades distintas: um fosfolipídeo denominado lipídio A, responsável pelo efeito tóxico, localizado na porção mais interna da molécula; um cerne polissacarídeo composto por cinco açúcares ligados ao lipídeo A; e um polissacarídeo externo consistindo em até 25 unidades repetidas de três a cinco açúcares, correspondente ao antígeno somático, ou também denominado de "O "(Levinson, 2016).

Os óleos essenciais além da ação antimicrobiana, também podem atuar sobre o epitélio intestinal, provocando alterações morfohistológicas do trato gastrointestinal, estimulando a produção de enzimas digestivas e pancreáticas, promovendo o aumento da digestibilidade e absorção de nutrientes (Hernández et al., 2004; Jamroz et al., 2006; Oetting et al., 2006; Jang et al., 2007; Basmacioğlu Malayoğlu et al., 2010; Zanini et al., 2011).

Por estas características, pode-se constatar que o efeito dos óleos essenciais de plantas que contenham timol e carvacrol em sua constituição pode obter melhora no desempenho e na taxa de crescimento de aves, além de menor possibilidade de resistência cruzada entre micro-organismos.

\section{Alecrim (Lippia gracilis Shauer) e suas propriedades}

A espécie Lippia gracilis Shauer conhecida usualmente como alecrim-da-chapada ou alecrim- 
de-serrote, pertence à Família Verbenaceae, é encontrada na região semiárida do nordeste brasileiro, principalmente nos estados do Piaú, Bahia, Sergipe, Paraíba e Pernambuco (Gomes et al., 2011). É um subarbusto pouco ramificado, com folhas aromáticas, que produzem óleos essenciais ricos principalmente em compostos fenólicos como timol e carvacrol (Albuquerque et al., 2006). Entretanto, estudos demonstraram variações quantitativas na composição química do óleo essencial, provavelmente devido a condições genéticas, não padronização de cultivos e clima (Gomes et al., 2011).

Os compostos químicos presentes no óleo essencial, principalmente os monoterpenos carvacrol e timol, das espécies do gênero Lippia têm apresentado forte ação contra bactérias e fungos (Gomes et al., 2011). Albuquerque et al. (2006) ao avaliarem a atividade antimicrobiana do óleo essencial de Lippia gracilis Schauer sobre fungos contaminantes testados em laboratórios de cultura de tecidos vegetais e contra bactérias endofíticas de helicônias, demostraram que o óleo essencial da L. gracilis Schauer possui ação antimicrobiana contra estes. Neste caso, ocorreu $100 \%$ de inibição contra os fungos Geotrichum candidum, Trichoderma viride, Torula herbarum, Paecillomyces sp., Aspergillus nidulans, Fusicoccum sp., Aspergillus flavus e Paecillomyces aeruginens; 95,58\% contra Curvularia lunata e de 89,40\% contra Aspergillus niger, com a utilização do óleo essencial.

Ainda de acordo com Albuquerque et al. (2006), as bactérias Salmonela choleraceuisdiarizonae, Enterobacter asburiae, Bacillus thuringiensis, Bacillus pumilis, Kleibsiella pneumoniae, Enterobacter hormaechei e Bacillus cereus também foram inibidas na presença do óleo essencial de $L$. gracilis, pelo método de plaqueamento, sendo esta ação associada à presença dos monoterpenos fenólicos carvacrol $(41,77 \%)$ e do timol $(10,13 \%)$.

O carvacrol (2-metil-5-(1-metiletil) -fenol) e seu isômero timol (5-metil-2-(1-metiletil)- fenol) (Figura 1) são monoterpenos contidos em diversas plantas aromáticas sendo biossintetizados a partir do $\gamma$-terpineno e do $\rho$-cimeno (Nostro e Papalia, 2012). Ambos possuem fórmulas moleculares similares $\left(\mathrm{C}_{10} \mathrm{H}_{14} \mathrm{O}\right)$ e pesos moleculares de 150,22 g $\mathrm{mol}^{-1}$, porém o carvacrol em temperatura ambiente apresenta-se na forma líquida, cuja solubilidade em água é de $830 \pm 10$ ppm (Nostro e
Papalia, 2012), enquanto que timol se encontra na forma de cristais (Holland et al., 2014).

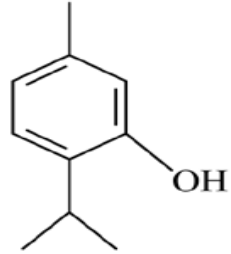

(1)

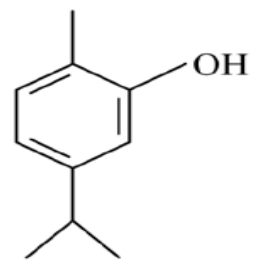

(2)
Figura 1. Estrutura química do timol (1) e carvacrol (2) principais constituintes do óleo essencial de alecrim (Lippia gracillis Shauer). Fonte: Lima e Cardoso (2007).

Estudos têm demonstrado que a atividade antimicrobiana no trato gastrointestinal dos animais está relacionada principalmente com a interação que estes compostos possuem com as membranas celulares dos diferentes microorganismos. O mecanismo de ação do timol e do carvacrol deve-se à capacidade que estes apresentam em atravessar a membrana celular do micro-organismo provocando alterações; capacidade esta que pode estar relacionada com as propriedades físico-químicas destas moléculas, considerando suas características lipofílicas e, ao mesmo tempo, devido a sua solubilidade em água (Cristani et al., 2007; Xu et al., 2008; Hammer e Heel, 2012; La Storia et al., 2011). A atividade antibacteriana pode ter relação com apenas um dos seus principais constituintes químicos, porém estudos afirmam que essa atividade também depende das interações entres eles (Michiels et al., 2007; García-García et al., 2011).

Segundo Singh et al. (2010), a ação antimicrobiana dos compostos fenólicos se dá através da regulação do metabolismo intermediário, ativando ou bloqueando reações enzimáticas, que interferem diretamente na síntese enzimática, seja em nível nuclear ou ribossomal, ou até mesmo alterando as estruturas de membranas dos micro-organismos, evitando seu crescimento ou multiplicação.

Santurio et al. (2011), ao avaliarem a atividade antibacteriana in vitro dos óleos essenciais de diferentes condimentos, observaram que os óleos essenciais que tem o timol e o carvacrol na sua composição, como o orégano, orégano mexicano e o tomilho, apresentaram atividade bactericida frente a Escherichia coli isolados de aves. Sendo que o óleo essencial de orégano apresentou atividade antimicrobiana 
superior aos outros óleos testados, possivelmente devido à maior concentração do carvacrol na sua composição.

Além da ação antimicrobiana, os compostos fenólicos presentes em muitos óleos essenciais apresentam ação antioxidante, pois agem como doadores de hidrogênio e, dessa forma, reduzem a produção de peróxidos de hidrogênio (Pereira e Maia, 2007). Com isso, o potencial antioxidante de um óleo essencial e seus compostos deve-se principalmente à capacidade de capturar radicais livres e à extinção do oxigênio reativo (Loizzo et al., 2009) (Figura 2).

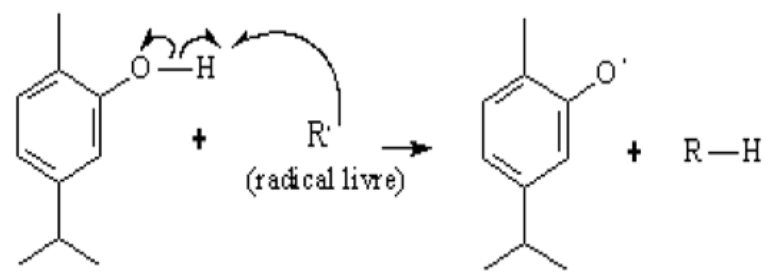

Figura 2. Carvacrol doando hidrogênio para o radical livre gerando radical estabilizado pelo anel aromático. Fonte: Lima e Cardoso (2007).

Luna et al. (2010), ao avaliarem a atividade antioxidante lipídica sobre a carcaça de frangos de corte Coob 500, observaram que a suplementação de $150 \mathrm{mg} / \mathrm{kg}$ de carvacrol ou de timol na ração teve a mesma eficácia que a suplementação com $150 \mathrm{mg} / \mathrm{kg}$ de BHT (hidroxitolueno butilado) na ração, antioxidante comumente usado como aditivo alimentar.

A efetividade dos compostos timol e carvacrol torna eficazes as ações antimicrobiana e antioxidante do óleo essencial de alecrim no organismo das aves, o que justifica seu uso como aditivo melhorador de desempenho para aves.

\section{Considerações Finais}

São escassos os trabalhos científicos que utilizaram o óleo de alecrim (Lippia gracilis Shauer) na dieta de aves como aditivo fitogênico. Devido à potencialidade que os compostos ativos apresentam diante de bactérias patogênicas e fungos, atividade antioxidante, assim como seu potencial como melhoradores de desempenho, o óleo essencial do alecrim torna-se um potencial aditivo para ser adicionado às dietas de aves.

\section{Agradecimentos}

À Fundação de Apoio à Pesquisa e a Inovação Tecnológica do Estado de Sergipe (FAPITEC) e ao Programa de Estímulo à
Mobilidade e ao Aumento da Cooperação Acadêmica da Pós-Graduação em Sergipe (PROMOB).

\section{Referências}

Agostini, P.S.; Solà-Oriol, D.; Nofrarías, M.; Barroeta, A.C.; Gasa, J.; Manzanilla, E.G. Role of in-feed clove supplementation on growth performance, intestinal microbiology, and morphology in broiler chicken. Livestock Science, 147: 113-118, 2012.

Albuquerque, C.C.; Camara, T.R.; Mariano, R.L.R.; Willadino, L.; Marcelino Júnior, C.; Ulisses, C. Antimicrobial action of the essential oil of Lippia gracilis Schauer. Brazilian Archives of Biology and Technology, 49(4): 527-535, 2006.

Andreatti-Filho, R.L. Paratifo aviário. In:

Saúde aviária e doenças. São Paulo: Roca Ltda, 2007. p.112-117.

Basmacioğlu Malayoğlu, H.; Baysal, Ş.; Misirlioğlu, Z.; Polat, M.; Yilmaz, H.; Turan, N. Effects of oregano essential oil with or without feed enzymes on growth performance, digestive enzyme, nutrient digestibility, lipid metabolism and immune response of broilers fed on wheat-soybean meal diets. British Poultry Science, 51(1): 67-80, 2010.

Bitu, V.; Botelho, M.A.; Costa, J.G.M.; Rodrigues, F.F.G.; Veras, H.N.H.; Martins, K.T.; Lyra, A.; Coluchi, G.G.; Ruela, R.S.; Queiroz, D.B.; Siqueira, J.S.; Quintans-Junior, L.J. Phythochemical screening and antimicrobial activity of essential oil from Lippia gracillis. Revista Brasileira de Farmacognosia Brazilian Journal of Pharmacognosy, 22(1): 69-75, 2012.

Bona, T.; Pickler, L.; Miglino, L.B.; Kuritza, L.N.; Vasconcelos, S.P.; Santin, E. Óleo essencial de orégano, alecrim, canela e extrato de pimenta no controle de Salmonella, Eimeria e Clostridium em frangos de corte. Pesquisa Veterinária Brasileira, 32: 411-418, 2012.

Brenes, A.; Roura, E. Essential oils in poultry nutrition: main effects and modes of action. Animal Feed Science and Technology, 158(1): 1-14, 2010.

Cardoso, V.S.; Lima, C.A.R.; Lima, M.E.F.; Dorneles, L.E.G.; Danelli, M.G.M. Piperine as a phytogenic additive in broiler diets. Pesquisa Agropecuária Brasileira, 47: 489-496, 2012. 
Callaway, T.; Edrington, T.S.; Anderson, R.C.; Harvey, R.B.; Genovese, K.J.; Kennedy, C.N.; Venn, D.W.; Nisbet, D.J. Probiotics, prebiotics and competitive exclusion for prophylaxis against bacterial disease. Animal Health Research Reviews, 9(2): 217-225, 2008.

Costa, L.B.; Tse, M.L.P.; Miyada, V.S. Extratos vegetais como alternativas aos antimicrobianos promotores de crescimento para leitões recém-desmamados. Revista Brasileira de Zootecnia, 36(3): 589-595, 2007.

Cristani, M.; D’Arrigo, M.; Mandalari, G.; Castelli, F.; Sarpietro, M.G.; Micieli, D.; Venuti, V.; Bisignano, G.; Saija, A.; Trombetta, D. Interaction of four monoterpenes contained in essential oils with model membranes: implications for their antibacterial activity. Journal of Agricultural and Food Chemistry, 55: 6300-6308, 2007.

Dorman, H.J.D.; Deans, S.G. Antimicrobial agents from plants: antibacterial activity of plant volatile oils. Journal of Applied Microbiology, 88: 308-316, 2000.

Fernandes, R.T.V; Arruda, A.M.V.; Oliveira, V.R.M.; Queiroz, J.P.A.F.; Melo, A.S.; Dias, F.K.D.; Marinho, J.B.M.; Souza, R.F.; Souza, A.O.V.; Filho, C.A.S. Aditivos fitogênicos na alimentação de frangos de corte: óleos essenciais e especiarias. PubVet, 9(12): 526535, 2015.

Ferro, M.M.; Moura, D.C.; Geron, L.J.V. Óleos essenciais em dietas para bovinos. Revista de Ciências Agroambientais, 14(2): 47-57, 2016.

Figueira, S.V.; Mota, B.P.; Leonídio, A.R.A.; Nascimento, G.M.; Andrade, M.A. Microbiota intestinal das aves de produção. Enciclopédia biosfera, 10(18): 2181-2208, 2014.

Flemming, J.S.; Freitas, R.J.S. Avaliação do efeito de prebióticos (MOS), probióticos (Bacillus licheniformis e Bacillus subtilis) e promotor de crescimento na alimentação de frangos de corte. Archives of Veterinary Science, 10(2): 41-47, 2005

García-García，R.; López-Malo, A.; Palou， E. Bactericidal action of binary and ternary mixtures of carvacrol, thymol, and eugenol against Listeria innocua. Journal Food Science, 76: 95-100, 2011.
Gomes, S.V.F.; Nogueira, P.C.L.; Moraes, V.R.S. Aspectos químicos e biológicos do gênero Lippia enfatizando Lippia gracilis Schauer. Eclética Química, 36(1): 64-77, 2011.

Hammer, K.A.; Heel, K.A. Use of multiparameter flow cytometry to determine the effects of monoterpenoids and phenylpropanoids on membrane polarity and permeability in Staphylococci and Enterococci. International Journal of Antimicrobial Agents, 40: 239-245, 2012.

Hentz, S.M.; Santim, N.C. Avaliação da atividade antimicrobiana do óleo essencial de alecrim (Rosmarinus officinalis 1.) contra Salmonella sp. Evidência, 7(2): 93-100, 2007.

Hernández, F.; Madrid, J.; Orengo, V.G.J.; Megías, M.D. Influence of two plant extracts on broilers performance, digestibility and digestive organ size. Poultry Science, 83: 169-174, 2004.

Holland, R.D.; Wilkes, J.G.; Cooper, W.M.; Alusta, P.; Williams, A.; Pearce, B.; Beaudoin, M.; Buzatu, D. Thymol treatment of bacteria prior to matrix-assisted laser desorption/ionization time-of-flight mass spectrometric analysis aids in identifying certain bacteria at the subspecies level. Rapid Communications in Mass Spectrometry, 28: 2617-2626, 2014.

Hong, J.C.; Steiner, T.; Aufy, A.; Lien, T.F. Effects of supplemental essential oil on growth performance, lipid metabolites and immunity, intestinal characteristics, microbiota and carcass traits in broilers. Livestock Science, 144: 253-262, 2012.

Humphrey, B.; Klasing, K. Modulation of nutrient metabolism and homeostasis by the immune system. World's Poultry Science Journal, 60(1): 90-100, 2004.

Huyghebaert, G.; Ducatelle, R.; Immerseel, F.V. An update on alternatives to antimicrobial growth promoters for broilers. The Veterinary Journal, 187(2): 182-188, 2011.

Ito, N.M.K.; Miyaji, C.I.; Lima, E.A.; Okabayshi, S. Saúde gastrointestinal, manejo e medidas para controlar as enfermidades gastrointestinais. In: Mendes, A.A.; Naas, I.A.; Macari, M. Produção de frangos de corte. Campinas: FACTA, 2004. p.205- 251.

Jamroz, D.; Wertelecki, T.; Houszka, M.; Kamel, C. Influence of diet type on the inclusion of plant origin active substances on morphological and histochemical 
characteristics of the stomach and jejunum walls in chicken. Journal of Animal Physiology and Animal Nutrition, 90: 255268, 2006.

Jang, I.S.; Ko, Y.H.; Kang, S.Y.; Lee, C.Y. Effect of a commercial essential oil on growth performance, digestive enzyme activity and intestinal microflora population in broiler chickens. Animal Feed Science and Technology, 134(3): 304-315, 2007.

Kohlert, C.; Van Rensen, I.; Marz, R.; Schindler, G.; Graefe, E.U.; Veit, M. Bioavailability and pharmacokinetics of natural volatile terpenes in animals and humans. Planta Medica, 66: 496-505, 2000.

Koiyama, N.T.G.; Rosa, A.P.; Padilha, M.T.S.; Boemo, L.S.; Scher, A.; Melo, A.M.S.; Fernandes, M.O. Desempenho e rendimento de carcaça de frangos de corte alimentados com mistura de aditivos fitogênicos na dieta. Pesquisa Agropecuária Brasileira, 49(3): 225-231, 2014.

La Storia, A.; Ercolini, D.; Marinello, F.; Di Pasqua, R.; Villani, F.; Mauriello, F. Atomic force microscopy analysis shows surface structure changes in carvacrol-treated bacterial cells. Research in Microbiology, 162: 164-172, 2011.

Lan, Y.; Verstegen, M.W.A.; Tamminga, S.; Williams, B.A. The role of the commensal gut microbial community in broiler chickens. World's Poultry Science Journal, 61(1): 95104, 2005.

Leahy, S.C.; Higgins, D.G.; Fitzegerald, G.F.; Van Sideren, D. Getting better with bifidobacteria. Journal of Applied Microbiology, 98: 13031315, 2005.

Leite, P.R.S.C.; Mendes, F.R.; Pereira, M.L.R.; Lima, H.J.A.; Lacerda, M. J.R. Aditivos fitogênicos em rações de frangos. Enciclopédia Biosfera, 8(15): 9-26, 2012.

Levinson, W. Estruturas de células bacterianas. In:_. Microbiologia médica e imunologia. Porto Alegre: Editora AMGH Ltda, 2016. p.414.

Lima, R.K.; Cardoso, M.G. Família Lamiaceae: Importantes óleos essenciais com ação biológica e antioxidante. Revista Fitos, 3(3): 14-24, 2007.

Loizzo, M.R.; Menichini, F.; Conforti, F.; Tundis, R.; Bonesi, M.; Saab, A.M.; Statti, G.A.; Cindio, B.; Houghton, P.J.; Menichini, F.; Frega, N.G. Chemical analysis, antioxidant, antiinflammatory and anticholinesterase activities of Origanum ehrenbergii Boiss and Origanum syriacum L. essential oils. Food Chemistry, 117: 174-180, 2009.

Lu, J.; Idris, U.; Harmon, B.; Hofacre, C.; Maurer, J.J.; Lee, M.D. Diversity and succession of the intestinal bacteria community of the maturing broiler chicken. Applied Environment Microbiology, 69: 6816-6824, 2003.

Luna, A.; Labaque, M.C.; Zygadlo, J.A.; Marin, R.H. Effects of thymol and carvacrol feed supplementation on lipid oxidation in broiler meat. Poultry Science, 89: 366-370, 2010.

Michiels, J.; Missotten, J.; Fremaut, D.; De Smet, S.; Dierick, N. In vitro dose-response of carvacrol, thymol, eugenol and transcinnamaldehyde and interaction of combinations for the antimicrobial activity against the pig gut flora. Livestock Science, 9: 157-160, 2007.

Nascimento, J.M.L.; Cavalcante, M.B.; Amarante, J.F.; Krewer, C.C.; Costa, M.M. Ação antimicrobiana de óleo essencial frente a cepas bacterianas contaminantes de alimentos. Acta Veterinaria Brasilica, 8(3): 221-225, 2014.

Névoa, M.L.; Caramori-Júnior, J.G.; Vieites, F.M.; Nunes, V.R.; Vargas-Junior, J.G.; Kamimura, R. Antimicrobianos e prebióticos nas dietas de animais não ruminantes. Scientia Agraria Paranaensis, 12(2): 85-95, 2013.

Nostro, A.; Papalia, T.; Antimicrobial Activity of carvacrol: current progress and future prospectives. Recent Patents on AntiInfective Drug Discovery, 7: 28-35, 2012.

Oetting, L.L.; Utiyama, C.E.; Giani, P.A.; Ruiz, U.S.; Miyada, V.S. Efeitos de extratos vegetais e antimicrobianos sobre a digestibilidade aparente, o desempenho, a morfometria dos órgãos e a histologia intestinal de leitões recém-desmamados. Revista Brasileira de Zootecnia, 35: 13891397, 2006.

Oviedo-Rondón, E.O.; Hume, M.E.; Hernández, C.; Clemente-Hernández, S. Intestinal microbial ecology of broilers vaccinated and challenged with mixed Eimeria species and supplemented with essential oil blends. Poultry Science, 85: 854-860, 2006.

Oviedo-Rondón, E.O. Molecular methods to evaluate effects of feed additives and nutrients in poultry gut microflora. Revista Brasileira de Zootecnia, 38: 209-225, 2009. 
Pereira, C.A.M.; Maia, J.F. Estudo da atividade antioxidante do extrato e do óleo essencial obtidos das folhas de alfavaca (Ocimum gratissimum L.). Ciência e Tecnologia de Alimentos, 27(3): 624-632, 2007.

Racanicci, A.M.C.; Danielsen, B.; Menten, J.F.M.; Regitano-D'Arce, M.A.B.; Skibsted, L.H. Antioxidant effect of dittany (Origanum dictamnus) in precooked chicken meat balls during chill-storage in comparison to rosemary (Rosmarinus officinalis). European Food Research Technology, 218: 521-524, 2004.

Racanicci, A.M.C.; Danielsen, B.; Skibsted, L.H. Mate (Ilex paraguariensis) as a source of water extractable antioxidant for use in chicken meat. European Food Research Technology, 227: 255-260, 2008.

Santos, B.M.; Pinto, A.S; Faria, J. E. Terapêutica e desinfecção em avicultura. $3^{\text {a }}$ ed. Viçosa: UFV, 2008. 87p.

Santurio, J.M.; Santurio, D.F.; Pozzatti, P.; Moraes, C.; Franchin, P. R.; Alves, S.H. Atividade antimicrobiana dos óleos essenciais de orégano, tomilho e canela frente a sorovares de Salmonella enterica de origem avícola. Ciência Rural, 37(3): 803-808, 2007.

Santurio, D.F.; Costa, M.M.; Maboni, G.; Cavalheiro, C.P.; Sa, M.F.; Pozzo, M.D.; Alves, S.H.; Fries, L.L.M. Atividade antimicrobiana de óleos essenciais de condimentos frente a amostras de Escherichia coli isoladas de aves e bovinos. Ciência Rural, 41(6): 1051-1056, 2011.

Silva, M.A.; Pessotti, B.M.S.; Zanini, S.F.; Colnago, G.L.; Rodrigues, M.R.A.; Nunes, L.C.; Zanini, M.S.; Martins, I.V.F. Intestinal mucosa structure of broiler chickens infected experimentally with Eimeria tenella and treated with essential oil of oregano. Ciência Rural, 39(5): 1471-1477, 2009.

Singh, P.; Shukla, R.; Prakash, B.; Kumar, A.; Singh, S.; Mishra, P.K.; Dubey, N.K. Chemical profile, antifungal, antiaflatoxigenic and antioxidant activity of Citrus maxima Burm. and Citrus sinensis (L.) Osbeck essential oils and their cyclic monoterpene, DL-limonene. Food and Chemical Toxicology, 48: 1734-1740, 2010.

Soares, K.A.; Resende, A.; Silva-Júnior, W.; Pandolfo, C. Avaliação da atividade antimicrobiana de extrato de alecrim-docampo (Baccharis dracunculifolia) sobre bactérias Gram negativas e Gram positivas. Ensaio e Ciência: Ciências Biológicas, Agrárias e da Saúde, 17(14): 17-28, 2013.

Teirlynck, E.; Bjerrum, L.; Eeckhaut, V.; Huygebaert, G.; Pasmans, F.; Haesebrouck, F.; Dewulf, J.; Ducatelle, R.; Immerseel, V. The cereal type in feed influences gut wall morphology and intestinal immune cell infiltration in broiler chickens. British Journal of Nutrition, 102(10): 1453-1461, 2009.

Teixeira, B.; Marques, A.; Ramos, C.; Neng, N.R.; Nogueira, J.M.F.; Saraiva, J.A.; Nunes, M.L. Chemical composition and antibacterial and antioxidant properties of commercial essential oils. Industrial Crops and Products, 43: 587-595, 2013

Toledo, G.S.P.; Costa, P.T.C.; Silva, L.P.; Pinto, D.; Ferreira, P.; Poletto, C. J. Desempenho de frangos de corte alimentados com dietas contendo antibiótico e/ou fitoterápico como promotores, adicionados isoladamente ou associados. Ciência Rural, 37(6): 1760-1764, 2007.

Traesel, C.K.; Lopes, S.T.A.; Wolkmer, P.; Schmidt, C.; Santurio, J.M.; Alves, S.H. Óleos essenciais como substituintes de antibióticos promotores de crescimento em frangos de corte: perfil de soroproteínas e peroxidação lipídica. Ciência Rural, 41(2): 278-284, 2011.

Valero, M.V.; Prado, R.M.; Zawadski, F.; Eiras, C.E.; Madrona, G.S.; Prado, I.N. Propolis and essential oils additives in the diets improved animal performance and feed efficiency of bulls finished in feedlot. Acta Scientiarum Animal Sciences, 32: 419-426, 2014.

Vasconcelos, F.C.; Bastos-Leite, S.C.; Gomes, T.C.L.; Goulart, C.C.; Sousa, A.M.; Fontenele, G.S.P. Ácidos orgânicos, óleos essenciais e simbiótico na dieta de poedeiras semipesadas: desempenho produtivo e análise econômica. Acta Veterinaria Brasilica, 10(3): 194-200, 2016.

Willing, B.; Van Kessel, A. Intestinal microbiota differentially affect brush border enzyme activity and gene expression in the neonatal gnotobiotic pig. Journal of Animal Physiology and Animal Nutrition, 93(5): 586-595, 2009 
Xu, J.; Zhou, F.; Ji, B.P.; Pei, R.S.; Xu, N. The antibacterial mechanism of carvacrol and thymol against Escherichia coli. Letters in Applied Microbiology, 47: 174-179, 2008.

Zanini, S.F.; Silva, M.A.; Pessotti, B.M.S.S.; Colnago, G.L.; Nunes, L.C.; Rodrigues, M.R.A.; Suplementação de vitamina E e/ou de óleo essencial de aroeira na dieta de frangos de corte sobre o desempenho e morfometria intestinal. Archives of Veterinary Science, 16(2):76-81, 2011.

Zhang, K.Y.; Yan, F.; Keen, C.A.; Waldroup, P.W. Evaluation of microencapsulated essential oils and organic acids in diets for broiler chickens. International Journal of Poultry Science, 4(9): 612-619, 2005. 